\title{
Application of Hand-held Terminal-Based Micro-Learning in Teaching
}

\author{
Xue Qin \\ Information Technology Department of Hubei University of Police, Wuhan 430034, Hubei
}

Email: superxueqin@163.com

\begin{abstract}
With the advance of technology and due to the universality and convenience of handheld terminal, the concept of life-long learning has been gradually interiorized. On this basis, hand-held terminal-based micro-learning emerges and develops in a rapid pace. This paper illustrates the concept and features of micro-learning, analyzes hand-held terminal-based micro-learning activity cases, and evaluates the micro-learning effect.
\end{abstract}

Keywords: Micro-learning; Wechat; Teaching

\section{Introduction}

According to 39th China Internet Network Development State Statistic Report released by CNNIC at Beijing, Jan 22nd, 2017, China cyber citizen scale has reached 731 million by December 2016, which is roughly equal to the total population of entire Europe, and China internet popularizing rate has reached $53.2 \%$. China Internet industry is undergoing a standardization and value-based development, moreover the mobile internet enhances the sharing of consumption mode, intellectualization of equipment, and diversification of scenario [1]. With the development of internet technology, current society has entered into micro age. Weibo, WeChat, Micro Film, Microfic Meme, Micro travel, which feature decentration, dynamic, fragmentization, and immediacy, have become emerging and dominant transmission mode and culture type, unconsciously changing people's living style and social way. As a product of this micro age, Weibo, WeChat, Micro-Video, Micro Course not only bring challenges to conventional internet applications, but also make great impact on people's learning mode. How to recover the shortage of conventional classroom teaching, explore self-learning mode and enhance learning efficiency with aid of micro-learning is of great significance in cultivation of innovative talents.

\section{Concept and features of micro-learning}

As defined by Baidu Wikipedia, micro-learning is a two-way communication learning mode with the aid of mobile communication technology, without the limitation of time and place. Micro-learning content, carried on micro media, is normally presented in practical and short content block, which allows people to learn short, loosely connected, self-contained knowledge or mode in limited time. Micro-learning content is normally loaded on but not limited to mobile terminals such as mobile phone or PDA. Therefore, micro media are needed to present micro-learning content, multiple mobile terminals are needed to load micro courses, and mobile communication devices are needed to realize interaction and communication of micro-learning [2].

Lindner, an Austrian expert on learning study, described micro-learning as a new type of learning existing in new media ecosystem based on micro content and micro media [3].

Professor Zhu Zhiting from East China Normal University illustrated micro-learning features, stressed the connotation and character contained in micro-learning content block, and proposed a new theory basis of microlearning-connectivism; On the basis of relevant concepts of microlearning proposed by foreign researchers, Professor Chen Weiwei and Professor Li Yi et al. concluded significant features of microleanring, including short time period, tiny fragment, individuation, and multi-media, etc [4]. 


\subsection{Features of microlearning}

Compared with conventional learning mode, microlearning has following major features

(1) Simple content

Microlearning content is normally expanded around a single topic and a core knowledge point, which observes features of short time, short content, loose connection, and fragmentation [5].

(2) Various types

The manifestation forms of microlearning content are various, including text, graph, sound, animation, audio, video and web link, etc. The various manifestation forms provide more options for the learners.

\section{(3) Convenient content carrier}

With the advance of technology, people can acquire microlearning resources via various portable mobile web terminals, such as smart mobile, PAD, mobile learning applications. Microlearning process and progress can be control by learner according to their own situations, without the limitation of book, which is pretty convenient.

(4) Flexible time and space for microlearning

Micro-learners can acquire learning resources via portable mobile web terminals at any time and any places. Learners can obtain more learning time through organizing fragmented time.

\section{Case design of hand-held terminal-based microlearning activity}

Computer Network is a professional basic course and compulsory course for students majored at computer science and technology, and information security. Currently, many China colleges and universities take Computer Network (the 7th edition) edited by Professor Xie Xiren as teaching material. Such book contains large amount of contents, and most colleges finish the first 6 chapters due to the limitation of class hour. If classing teaching content can be extended to out-class teaching via portable hand-held terminals by adopting microlearning strategy, the problem of class hour limitation will be resolved on one hand, and the self-learning ability of students can be cultivated on the other hand.

\subsection{Learner}

A questionnaire survey was conducted among 89 students majored in information security in class of 2014 from Hubei University of Police. Results show that $90 \%$ of students are interested in learning such course, $84 \%$ students think the class hour of $4 \mathrm{~h}$ per week is not enough, $92 \%$ students will continue to learn such course at out-class. In addition, some students take part in various volunteer service and community activities, and thus sometime are absent from class. Therefore, they cannot well master the content taught at classroom, and hope to communicate with teachers via WeChat or QQ to better understand what they have learnt. Moreover, statistic data show that $95 \%$ of students have at least one mobile phone, in which smart phone accounts for $99 \%$, and they take mobile phone with them, $25 \%$ of students have PAD. They have large amounts of fragmented time that can be utilized every day.

\subsection{Content of microlearning}

Taking certain chapter of "preparation of twisted-pair RJ-45 joint" in Computer Network Course as example, teaching sources are designed, hoping that students can learn the functions of pin-outs of RJ-45joint, and master the preparation method of straight-through wire, cross cable, and rollover cable.

\subsection{Environment of microlearning}

When students are in noisy environments, such as playground, dining hall, outdoors, it will be difficult to get down to learn, while if they are in quiet environments like classroom, library, or dormitory, they can conduct microlearning using fragmented time.

\subsection{Learning resource design}


Hand-held terminal-based course resources are main content of microlearning. However due to the limitation of broadband, immediacy requirement and difference in manifestation mode, design principle should be considered in content and interface design, file size, and information push mechanism.

(1) Content: The time cost for microlearning content should be controlled within $30 \mathrm{~s}$ to $5 \mathrm{~min}$ [6]. Microlearning content should be in micro-scale, moderate difficulty, clear expression, loosely connected, allowing students to learn at any time and any place. For example, regarding the chapter of "preparation of twisted-pair RJ-45 joint", we can send the concept of twisted-pair cable and application scenarios onto WeChat group, allowing them to download via mobile terminal.

(2) Interface design: user-friendly, high feasibility. Since the screen of a mobile phone is small, the content on mobile screen should be expressed briefly, with descriptive graph, animation, audio, video, reaching high-efficiency guiding effect.

(3) File size: due to the limitation of transport bandwidth, microlearning file size should not be large. Reduce embellish parts in file, and control web transmission cost as much as possible.

(4) Content push mechanism: Micro-learners use fragmented time to learn, a overloaded content is easy to interference learner's normal study and life, causing inimical emotion, therefore, the released content should be small but high-quality.

\subsection{Microlearning activity design}

(1) Task design: by learning basic knowledge about twisted pair, make straight-through cable, cross cable, rollover cable using twisted-pair, RJ-45 joint, wire stripper and cable tester, and then test if it can work.

(2) Activity procedure: first learn basic knowledge on preparation of twisted-pair RJ-45 joint, and the make straight-through cable, cross cable, rollover cable.

(3) Activity form: self-learning, problem-solving microlearning activities, such as reading, problem sovling.

(4) Guiding strategy: provide strategies for micro-learners, such as designing "matters need attention" and "tips" for them.

(5) Final evaluation: test if the prepared straight-through cable, cross cable, rollover cable can work using cable tester, and give self-assessment,

(6) Problem feedback: Communicate with other learner using instant messaging software such as WeChat and QQ, and provide reference for improvement of microlearning activity design.

Outcome form: successfully make straight-through cable, cross cable, rollover cable, and apply them into different scenarios.

\section{Evaluation of microlearning effect}

After finishing course, a secondary questionnaire survey was performed among 89 students majored in information security in Class of 2014 of Hubei University of Police. Results show that $80 \%$ of students believe hand-held terminal-based microlearning can enhance learning enthusiasm and self-learning ability; $76 \%$ of students will review course content on WeChat in their spare time; $68 \%$ of students will discuss with classmates or teachers on learning content; $76 \%$ of students believe hand-held terminal-based microlearning can cover the shortages of conventional classroom teaching, especially for those who often need to go out for volunteer service. However, $32 \%$ of students think they may do something unrelated with learning on mobile phone during microlearning process.

As a new learning form, hand-held terminal-based microlearning can allow students study at any time and any place, which can effectively enhance initiative of learning. Most students will review course content on WeChat using their fragmented time. When a question occurs, they will seek help from 
classmates or teachers via hand-held terminal, so as to reach a sound communication with others and establish a good learning atmosphere. In addition, such learning form can effectively integrate mobile learning resources, and optimize mobile learning courses. Although microlearning is still at an early stage, with the progress on this issue, it will eventually promote and optimize mobile learning development.

\section{Acknowledgement}

Foundation item: The Second Batch of Key Teaching Research Programs of Hubei University of Police in 2015 "Application of Hand-held Terminal-Based Microlearning in Teaching"; The Third Batch of Key Teaching Research Programs of Hubei University of Police in 2015 "Microlearning-Based Self-learning Mode in Mobile Internet Environment"; 2016 Hubei Provincial Education Science Planning Topic "Research of Educational Public Sentiment Monitoring Technique and Guiding Strategy under Internet Plus Environment" (2016GB061).

\section{References}

[1] The 39th China Internet Network Development State Statistic Report [EB/OL]. http://www.cnn ic.net.cn/hlwfzyj/hlwxzbg/hlwtjbg/201701/t20170122_66437.htm

[2] Microlearning [EB/OL]. http://baike.baidu.com/item/Microlearning.

[3] Zhu Zhiting, Zhang Hao, Gu Xiaoqing. A Practical Informal Learning Mode-Microlearning [J]. China Educational Technology, 2008, (2).

[4] Yang Zhihe, Gu Xiaoqing, Zhu Zhiting. New Development of CSCL Support Technology [J]. China Educational Technology,2009(12):110-115.

[5] Martin Lindner. Micromedia Flow Experience Design. A Conceptual Framework for

Designing Microcontent-driven Applications for Peripheral View and Partial Attention [A] Proceedings of the 4th International Microlearning 2008 Conference:

37-56. Conference: 179-186.

[6] Chen Mingming. Initiation and Evaluation of Mobile Learning Resources [J]. Primary and Middle School Educational Technology, 2010,(9). 